\title{
Carnosic acid induces apoptosis through inactivation of Src/STAT3 signaling pathway in human renal carcinoma Caki cells
}

\author{
JI EUN PARK ${ }^{1 *}$, BYOUNGDUCK PARK ${ }^{1 *}$, IN GYEONG CHAE ${ }^{1}$, DO-HEE KIM ${ }^{2}$, \\ JUTHIKA KUNDU ${ }^{1}$, JOYDEB KUMAR KUNDU ${ }^{1}$ and KYUNG-SOO CHUN ${ }^{1}$ \\ ${ }^{1}$ College of Pharmacy, Keimyung University, Daegu 704-701; ${ }^{2}$ College of Pharmacy, \\ Seoul National University, Seoul 151-742, Republic of Korea
}

Received November 25, 2015; Accepted December 31, 2015

DOI: $10.3892 /$ or.2016.4642

\begin{abstract}
Carnosic acid (CA), the major bioactive compound of Rosmarinus officinalis L., has been reported to possess anti-inflammatory and anticancer activities. However, the molecular mechanisms underlying the anticancer effects of CA remain poorly understood. In the present study, we investigated that CA significantly reduced the viability of human renal carcinoma Caki cells. CA-induced apoptosis was connected with the cleavage of caspase- $9,-7$ and -3 , and that of PARP. Moreover, CA increased the expression of pro-apoptotic protein Bax and diminished the expression of anti-apoptotic protein $\mathrm{Bcl}-2$ and $\mathrm{Bcl}-\mathrm{xL}$, thereby releasing cytochrome $\mathrm{c}$ into the cytosol. Treatment with CA in Caki cells also induced the expression of p53 and its target gene product, p27, through down-regulation of Murine double minute-2 (Mdm2). Furthermore, CA generated reactive oxygen species (ROS), and pretreatment with ROS scavenger $N$-acetyl cysteine (NAC) abrogated CA-induced cleavage of PARP and expression of p53. One of the key oncogenic signals is mediated through signal transducer and activator of transcription-3 (STAT3), which promotes abnormal cell proliferation. Incubation of cells with CA markedly diminished the phosphorylation of STAT3 and its upstream, Src, and reduced the expression of STAT3 responsive gene products, such as D-series of cyclins and survivin. Taken together, the present study revealed that CA induced apoptosis in Caki cells by induction of p53 and suppression of STAT3 signaling.
\end{abstract}

Correspondence to: Professor Kyung-Soo Chun, College of Pharmacy, Keimyung University, 1095 Dalgubeoldaero, Dalseo-Gu, Daegu 704-701, Republic of Korea

E-mail: chunks@kmu.ac.kr

"Contributed equally

Key words: carnosic acid, apoptosis, reactive oxygen species, signal transducer and activator of transcription-3, renal cancer

\section{Introduction}

Renal cell carcinoma (RCC) represents the most common malignant tumor of the kidney. The overall incidence of RCC increases significantly from the age of 50 to 70 years $(1,2)$. With high degree of heterogeneity, RCC exhibits poor prognosis because of increased rate of metastasis and resistance to conventional chemotherapy and radiotherapy (3). Therefore, alternative novel therapeutic agents are needed for effective treatment of RCC. Since the evasion from apoptosis is one of the hallmarks of cancer, it has long been attempted to develop anticancer drugs that can selectively induce apoptosis in cancer cells (4). A wide variety of natural products, especially phytochemicals, have been shown to suppress cell growth, modulate cell differentiation and induce cancer cell death (5).

Apoptosis, a physiological process of forcing unwanted cells to commit suicide, is characterized by cell shrinkage, plasma membrane blebbing. DNA fragmentation and the formation of apoptotic bodies (6). Biochemical mechanisms of apoptosis involve two different pathways, one is the intrinsic or the mitochondria-mediated pathway, and the other is the extrinsic or death receptor (DR)-mediated pathway (7). The intrinsic pathway involves disruption of mitochondrial membrane potential and the release of cytochrome $\mathrm{c}$ from the mitochondrial inter-membrane space into the cytosol, resulting in the activation of caspase- $9,-7$ and -3 through the proteolytic cleavage of respective pro-caspases (8). The mitochondrial membrane potential is regulated by proteins of the B cell lymphoma-2 (Bcl-2) family (9). These include anti-apoptotic $\mathrm{Bcl}-2$ proteins (Bcl-2 and $\mathrm{Bcl}-\mathrm{xL}$ ), pro-apoptotic multidomain protein (Bak and Bax), and BH-3-only pro-apoptotic proteins (Bad, Bid and Bim) (10). Alteration in cellular redox status shifts the balance between the expression of anti-apoptotic and pro-apoptotic proteins, thereby leading to cell fate decision (11). A critical determinant of cell fate decision is the intracellular accumulation of reactive oxygen species (ROS), which are generated as by-products of cellular metabolism. High levels of ROS may lead to cell death through mitochondrial collapse (12).

The extrinsic pathway, on the contrary, is activated by death-inducing signal molecules of tumor necrosis factor 
(TNF) family, such as FasL, TNF and TNF-related apoptosis inducing ligand (TRAIL) (13), which bind to various plasma membrane-bound DRs (14). Upon stimulation of an appropriate apoptotic signal, the activation of DRs leads to the formation of the death-inducing signaling complex (DISC) and the activation of caspase- 8 and -10 , which in turn activates the rest of downstream caspases, such as caspase-3, thereby inducing apoptosis (15). A number of plant polyphenols have been reported to induce apoptosis via the intrinsic or extrinsic pathway in various cancer cells (16).

Signal transducer and activator of transcription-3 (STAT3) plays a decisive role in regulating cell growth, survival, angiogenesis and immune escape of tumor cells (17). The blockade of STAT3 signaling caused induction of apoptosis, inhibition of cell proliferation, suppression of angiogenesis and stimulation of immune responses (18-21). In cancer cells, STAT3 becomes constitutively active through the phosphorylation by upstream Src family kinases or Janus-activated kinases (Jaks) (19). Since the STAT3-regulated gene products, such as Bcl-xL, Bcl-2, survivin, c-Myc and D-series of cyclins are involved in enhanced cell proliferation, selective inhibition of STAT3 signaling can suppress proliferation and induce apoptosis in cancer cells (19). Previous studies have shown that suppression of STAT3 signaling inhibits the growth of various cancer cells including those of the stomach, liver, head and neck, skin, and lung (22). STAT3, a signal mediator of various pro-inflammatory cytokines and growth factors acting constitutively in an inflammatory tumor microenvironment, is an important molecular target of various anticancer drugs (23).

Rosmarinus officinalis L., generally known as rosemary, has a long-standing repution for improving memory and has been used as a symbol of reminiscence in Europe (24). In addition, leaves of the plants have been used as a means to weight loss due to its ability to inhibit lipid absorption activities in the digestive system (25). Major bioactive components of the plant include polyphenolics, such as carnosic acid (CA), carnosol, rosmarinic acid and ursolic acid (26-29). CA (Fig. 1A) has a wide range of biological activities, including antioxidant, anticancer, anti-inflammatory, anti-adipogenic and neuroprotective effects (30-34). The present study investigated the underlying molecular mechanisms of anticancer effects of CA in human renal carcinoma (Caki) cells. We found that CA induced anti-proliferative and apoptotic effects in Caki cells through mitochondria-dependent caspase activation and the interference with STAT3 signaling pathway via the generation of ROS.

\section{Materials and methods}

Materials. CA (purity 99\%) and $N$-acetyl cysteine (NAC) were purchased from Sigma-Aldrich (St. Louis, MO, USA). Antibodies against cleaved caspase-9, -7, -3, poly(ADP-ribose) polymerase (PARP), Bcl-2, Bcl-xL, Bax, cytochrome c, STAT3, p-STAT3 (Y705), p-STAT3 (S727), Src, p-Src, cyclin D1, D2, and D3 and survivin were from Cell Signaling Technology Inc. (Beverly, MA, USA). Antibody against each of $\mathrm{p} 53$, murine double minute-2 (Mdm2), p27, and horse-raddish peroxidase-conjugated secondary antibodies were from Santa Cruz Biotechnology (Paso Robles, CA, USA). $\beta$-Actin antibody was obtained from Sigma Chemical Co. (St. Louis, MO,
USA). The 2'-7' dichlorofluorescin diacetate (DCF-DA) was from Invitrogen (Carlsbad, CA, USA). Hank's balanced salt solution (HBSS) was from the Meditech (Herndon, VA, USA).

Cell culture and treatment. Caki cells were obtained from Dr T.K. Kwon (Keimyung University, Korea) and maintained in Dulbecco's modified Eagle's medium (DMEM) supplemented with $10 \%$ fetal bovine serum and antibiotics (100 U/ $\mathrm{ml}$ penicillin $\mathrm{G}$ and $100 \mathrm{mg} / \mathrm{ml}$ streptomycin) at $37^{\circ} \mathrm{C}$ in a humidified incubator containing 5\% $\mathrm{CO}_{2}$ and $95 \%$ air. In all the experiments, cells were seeded at $1 \times 10^{5}$ cells/well and incubated with CA at 50-60\% confluence. All chemicals were dissolved in ethanol and the final ethanol concentration was $<0.1 \%$.

Cell viability assay. The cell growth effect was measured by the MTT assay. Cells $\left(2 \times 10^{3}\right)$ were incubated in triplicate in a 96-well plate in presence or absence of CA in a final volume of $100 \mu \mathrm{l}$ for different time intervals at $37^{\circ} \mathrm{C}$. Thereafter, $10 \mu \mathrm{l}$ of MTT solution $(5 \mathrm{mg} / \mathrm{ml})$ was added to each well and incubated for $4 \mathrm{~h}$. Medium was removed, formazan was dissolved in DMSO and absorbance at $550 \mathrm{~nm}$ was measured by using microplate reader (Tecan Trading AG, Männedorf, Switzerland). Cell viability was described as the relative percentage of control.

Annexin $V$ staining. Annexin $\mathrm{V}$ staining was performed using fluorescein isothiocyanate (FITC)-Annexin V staining kit (BD Biosciences, San Jose, CA, USA) following the manufacturer's instructions. Briefly, CA-treated cells were washed with PBS and resuspended in binding buffer containing Annexin $\mathrm{V}$ and propidium iodide (PI). Flourescence intensity was measured using flow cytometry (BD Biosciences).

Western blot analysis. Cells were harvested and lysed with RIPA buffer, and the resulting protein samples were quantified by using bicinchoninic acid protein assay kit (Pierce Biotechnology, Rockford, IL, USA). Equal amount of protein extracts were denatured by boiling at $100^{\circ} \mathrm{C}$ for $5 \mathrm{~min}$ in sample buffer. The proteins were separated on 8-12\% sodium dodecyl sulfate polyacrylamide gel electrophoresis (SDS-PAGE) and transferred to polyvinylidene difluoride membrane. The membranes were blocked with 5\% skim milk in Tris-buffered saline with Tween-20 buffer (TBS-T) $(10 \mathrm{mM}$ Tris, $150 \mathrm{mM}$ $\mathrm{NaCl}, \mathrm{pH} 7.5$ and $0.1 \%$ Tween-20) for $1 \mathrm{~h}$ at room temperature. The membranes were washed 3 times for $10 \mathrm{~min}$ each with TBS-T buffer and incubated for $1 \mathrm{~h}$ with horseradish peroxidase-conjugated secondary antibodies. The membranes were washed 3 times for $10 \mathrm{~min}$ each with TBS-T buffer. Immunoblot membranes were incubated with Super-signal pico-chemiluminescent substrate or dura-luminol substrate (Thermo Scientific, Waltham, MA, USA) according to manufacturer's instruction and visualized with imagequant ${ }^{\mathrm{TM}} \mathrm{LAS}$ 4000 (Fujifilm Life Science, Tokyo, Japan).

Measurement of reactive oxygen species (ROS) accumulation. Cells were treated with CA in the presence or absence of NAC for $24 \mathrm{~h}$ and then loaded with $25 \mu \mathrm{M}$ of $2^{\prime} 7^{\prime}$-dichlorofluorescin diacetate (DCF-DA). After incubation for $30 \mathrm{~min}$ at $37^{\circ} \mathrm{C}$ in a $5 \% \mathrm{CO}_{2}$ incubator, cells were washed twice with HBSS 
A<smiles>CC(C)c1cc2c(c(O)c1O)C1(C(=O)O)CCCC(C)(C)C1CC2</smiles>

C

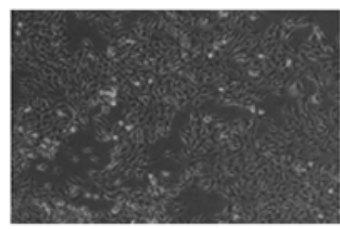

Control

D

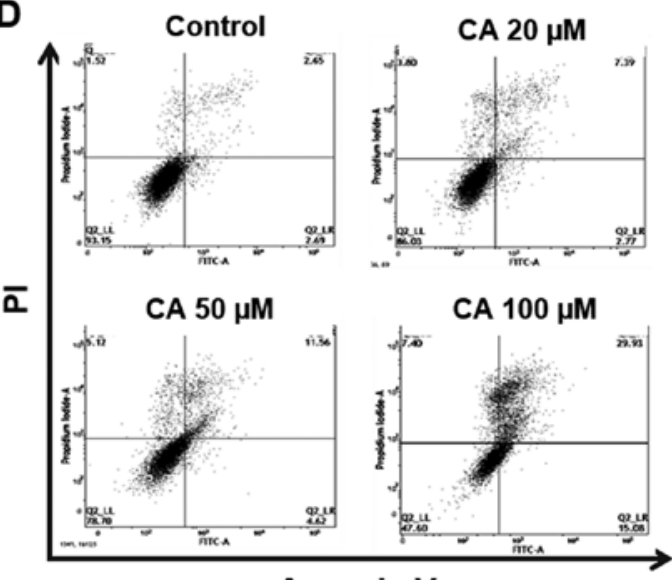

20
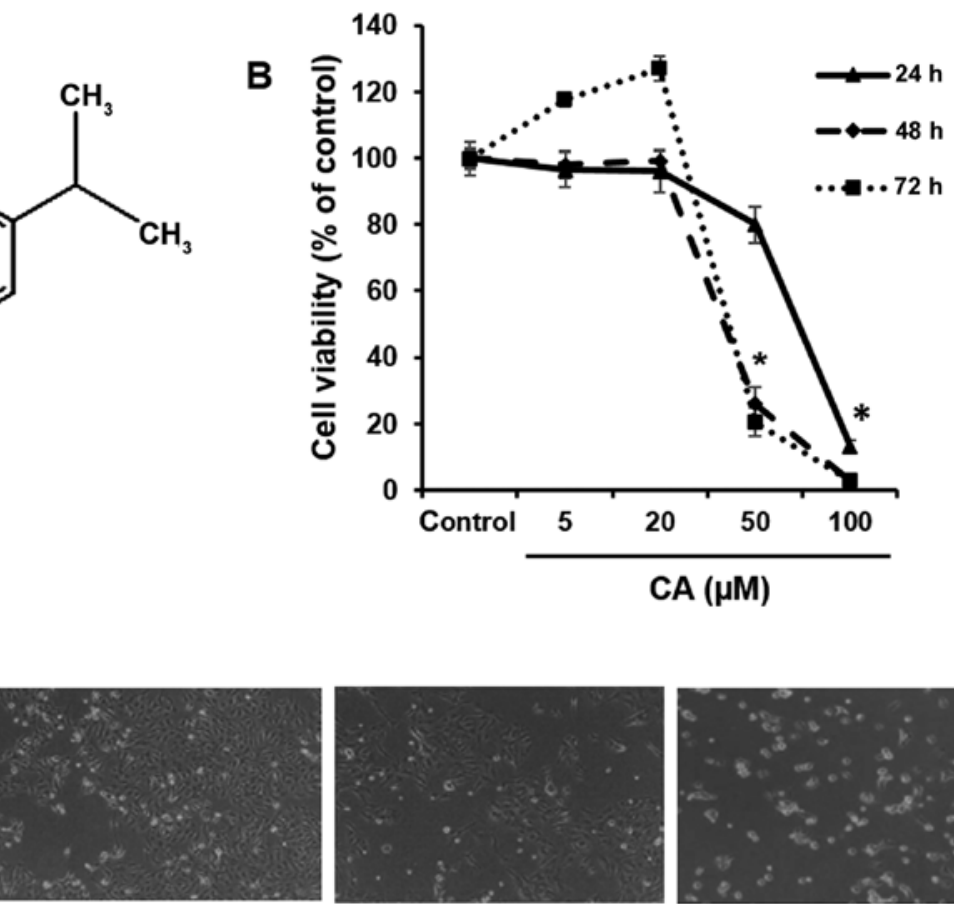

50

$\mathrm{CA}(\mu \mathrm{M})$

E

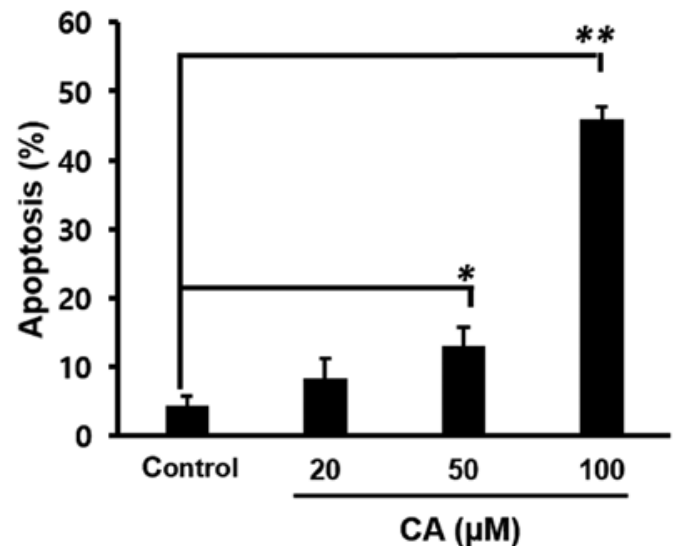

Figure 1. Cytotoxic effect of carnosic acid (CA) in Caki cells. (A) Chemical structure of CA. (B) Caki cells were treated with indicated concentrations of CA for 24,48 or $72 \mathrm{~h}$. Cell viability was determined by the MTT assay. Values are expressed as means \pm SD. "p $<0.001$, compared to control. (C) Cells were treated with indicated concentrations of CA for $24 \mathrm{~h}$ and cell morphology was analyzed by microscopy (x200). (D) The apoptotic index (\%) was determined by flow cytometry upon treatment of cells with CA $(20,50$ or $100 \mu \mathrm{M})$ for $24 \mathrm{~h}$ and staining with Annexin V and PI. (E) This graph shows statistical analysis of apoptosis. Data are representative of three independent experiments. " $\mathrm{p}<0.05,{ }^{* *} \mathrm{p}<0.001$, compared to control.

solution, suspended in the complete media and were examined under a fluorescence microscope to detect the intracellular ROS. Fluorescence of oxidized DCF was also measured at an excitation wave length of $480 \mathrm{~nm}$ and emission wavelength of $525 \mathrm{~nm}$ using flow cytometry.

Electrophoretic mobility gel shift assay (EMSA). The nuclear extract was prepared from cells incubated with or without CA. The STAT3 oligonucleotide probe 5'-AGC TTC ATT TCC CGT AAA TCC CTA-3' (Biomedic, Korea) was labeled with $\left[\gamma_{-}{ }^{32} \mathrm{P}\right]-A T P$ using T4 polynucleotide kinase. The EMSA was performed according to the protocol described earlier (35).
Statistical analysis. When necessary, data were expressed as mean \pm SD of at least three independent experiments, and statistical analysis for single comparison was performed using the Student's t-test and p-value $<0.05$ was considered to indicate a statistically significant difference.

\section{Results}

CA induces apoptosis in Caki cells. In the present study, the effect of CA on the viability of Caki cells was first examined by the MTT assay. As shown in Fig. 1B, treatment of Caki cells with CA significantly reduced the cell viability in a 
A

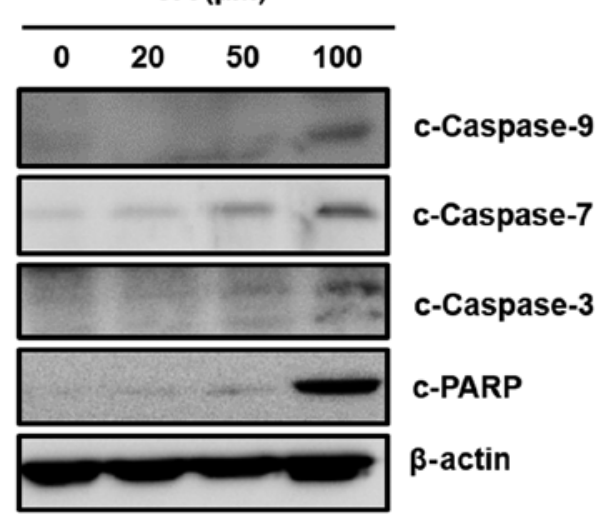

B

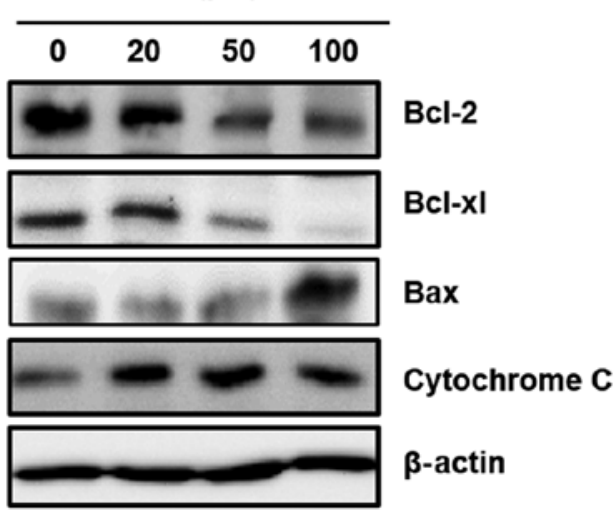

C

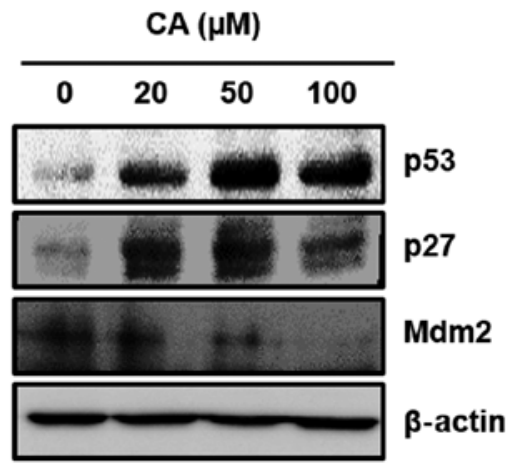

Figure 2. Effect of carnosic acid (CA) on cellular markers of apoptosis in Caki cells. Cells were treated with indicated concentrations of $\mathrm{CA}$ for $24 \mathrm{~h}$. (A) Immunoblot analysis for detecting the levels of cleaved caspase-9, -7 and -3 , and cleaved PARP. (B) The expression level of Bcl-2, Bcl-xL, Bax and cytochrome c. (C) Western blot analysis of p53, p27 and Mdm2 expression after $24 \mathrm{~h}$ incubation the cells with CA. Data are representative of three different experiments. $\beta$-actin was used as a loading control.

concentration- and time-dependent manner in comparison to the untreated cells. Fig. 1C showed the morphological changes of Caki cells upon incubation with varying concentrations of CA. At the highest concentration, the cell viability was inhibited approximately by $80 \%$ as compared to untreated cells after $24 \mathrm{~h}$. Based on this result, cells were incubated with CA at a range of concentrations $(20-100 \mu \mathrm{M})$ for a period of $24 \mathrm{~h}$ in subsequent experiments. To elucidate whether CA-mediated cytotoxicity could result from the induction of apoptosis, FACS analysis was performed. Caki cells treated with CA $(20,50$ or $100 \mu \mathrm{M})$ for $24 \mathrm{~h}$ were analyzed by flow cytometry using double staining with Annexin V and PI to quantify the population of cells undergoing apoptosis (Annexin $\mathrm{V}^{+} / \mathrm{PI}^{-}$). The results showed that the treatment of cells with CA markedly increased the percentages of apoptotic cells as compared with untreated control cells (Fig. 1D). Quantification of apoptotic cells and statistical analysis of CA-induced apoptosis are presented in Fig. 1E.

CA induces apoptosis through the mitochondrial pathway in Caki cells. Caspases are crucial components of the apoptosis pathway. The mitochondrial and caspase pathways are interconnected. Release of cytochrome c into the cytosol activates the caspase adaptor Apaf-1 and procaspase-9, which activates executioner caspases (caspase-3, -6 and -7) (36). In the present study, incubation of Caki cells with CA $(20,50$ or $100 \mu \mathrm{M})$ induced activation of caspase- $9,-7$ and -3 and the cleavage of
PARP (Fig. 2A), indicating the involvement of mitochondria in CA-induced apoptosis. Since Bcl-2 family proteins regulate the mitochondrial membrane integrity, the effect of CA on the expression of Bcl-2 family proteins was then examined. The present study revealed that CA not only downregulated the expression of anti-apoptotic protein $\mathrm{Bcl}-2$ and $\mathrm{Bcl}-\mathrm{xL}$, but also increased the expression of apoptosis inducing protein Bax, thereby releasing cytochrome $\mathrm{c}$ into the cytosol (Fig. 2B). As shown in Fig. 2C, incubation of cells with CA increased expression of p53 and diminished protein level of its cytosolic repressor protein $\mathrm{Mdm} 2$ in a concentration-dependent manner. p53 induces the cell cycle arrest through transcriptional activation of its cell cycle regulatory gene product, p27. We examined whether CA treatment has an effect on p27 expression in Caki cells. As a result, expression of p27 is increased by CA treatment in according to $\mathrm{p} 53$ protein levels.

Involvement of ROS in CA-induced apoptosis in Caki cells. Since the accumulation of intracellular ROS can induce cell death, the effect of CA on ROS generation was examined. Treatment of cells with CA $(20,50,100 \mu \mathrm{M})$ for $24 \mathrm{~h}$ generated ROS as revealed by the immunofluorescence analysis after DCF-DA staining (Fig. 3A) as well as by the FACS analysis (Fig. 3B). Pretreatment of cells with NAC abolished CA-induced ROS accumulation (Fig. 3C and D). Quantification and statistical analysis of CA-induced ROS generation are presented in Fig. 3E. 
A

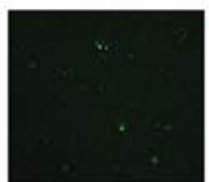

Control

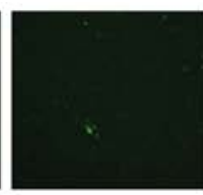

20

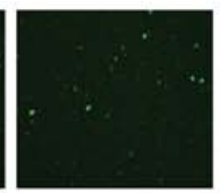

50

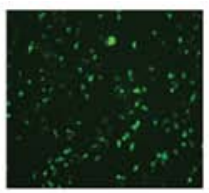

100

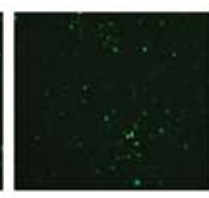

$\mathrm{H}_{2} \mathrm{O}_{2}$

$\mathrm{CA}(\mu \mathrm{M})$

B

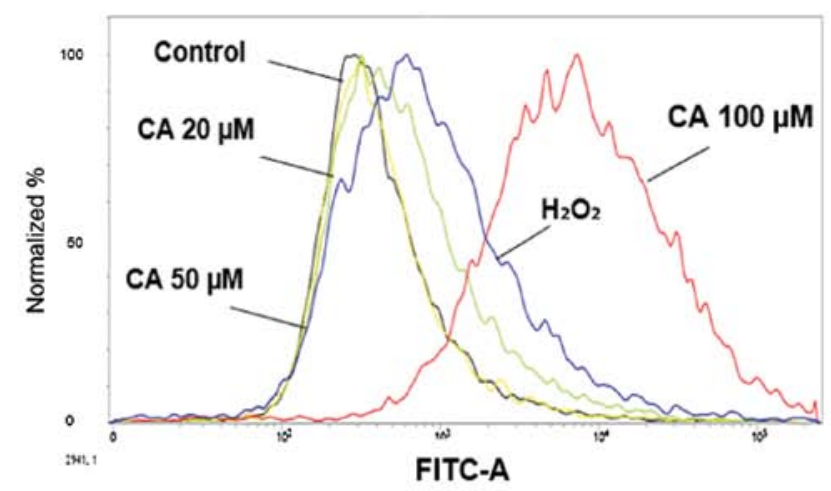

D

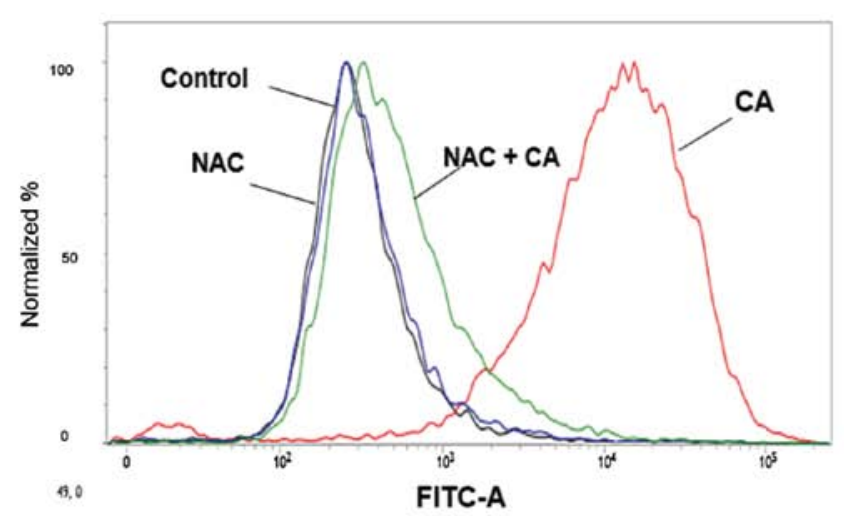

C

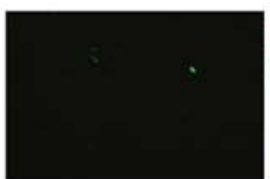

Control

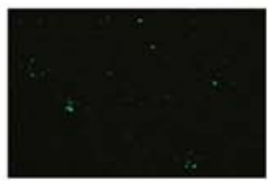

$\mathrm{NAC}+\mathrm{CA}$

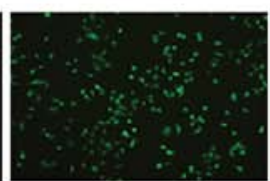

CA

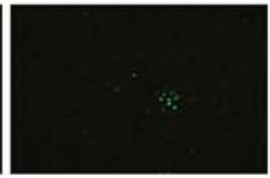

NAC
$E$

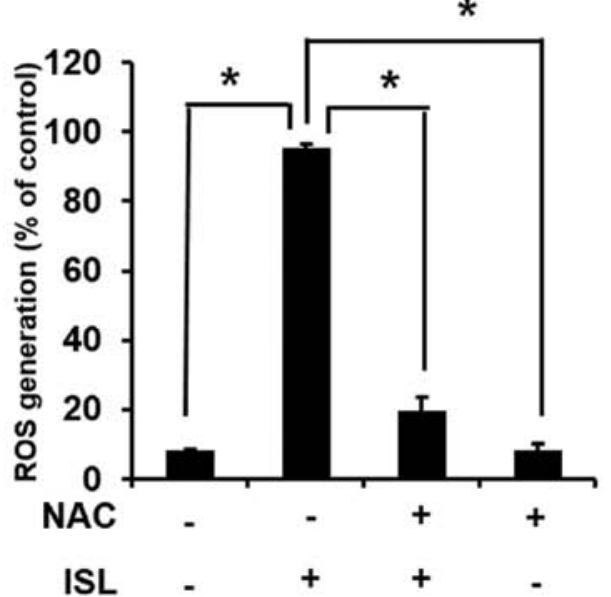

Figure 3. Carnosic acid (CA) induces the generation of ROS in Caki cells. (A and B) Cells were treated with CA (20, 50 or $100 \mu \mathrm{M})$ for $24 \mathrm{~h}$ and then examined for the intracellular accumulation of ROS (A) under a fluorescence microscope using DCF-DA fluorescence staining method (x200) or (B) measured by flow cytometry. (C and D) Cells were treated with NAC $(5 \mathrm{mM}) 1 \mathrm{~h}$ before treatment with CA $(100 \mu \mathrm{M})$ for $24 \mathrm{~h}$. ROS levels were measured either by (C) fluorescence microscopy or (D) by flow cytometry. (E) The graph shows quantification and statistical analysis of ROS generation by CA treatment in the presence or absence of NAC. The experiment was done in triplicate and the data presented as mean \pm SD. * $p<0.001$, compared to control.

CA attenuates the activation of STAT3 signaling pathway. Since STAT3 plays a key role in cell proliferation through transcriptional activation of pro-survival genes, we examined the effect of CA on the expression of cell proliferation markers, which are transcriptionally regulated by STAT3. The present study showed that CA diminished the constitutive phosphorylation at both Y705 and S727 residues of STAT3 (Fig. 4A). CA also reduced the constitutive STAT3 DNA-binding activity (Fig. 4B). In addition, CA treatment suppressed the expression of STAT3-regulated cell proliferative gene products, such as c-Myc, survivin and D-series of cyclins (Fig. 4C). STAT3 is known to be phosphorylated by upstream kinase, such as Src.
Since CA was found to suppress STAT3 activation, the effect of CA on the activation of upstream signaling proteins of STAT3 were checked. As shown in Fig. 4D, CA treatment resulted in the suppression of Src phosphorylation in concentrationdependent manner in Caki cells.

Role of ROS in CA-induced inhibition of STAT3 signaling and induction of apoptosis in Caki cells. We next examined the role of CA-induced ROS generation in blocking STAT3 signaling and induction of apoptosis in Caki cells. Treatment with CA in the absence or presence of NAC revealed that inhibition of ROS generation abrogated the inhibitory effect 
A

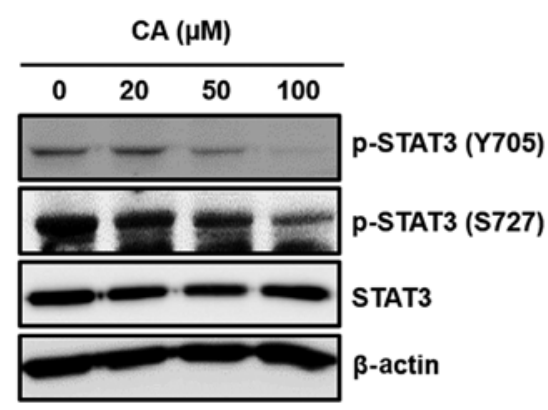

C

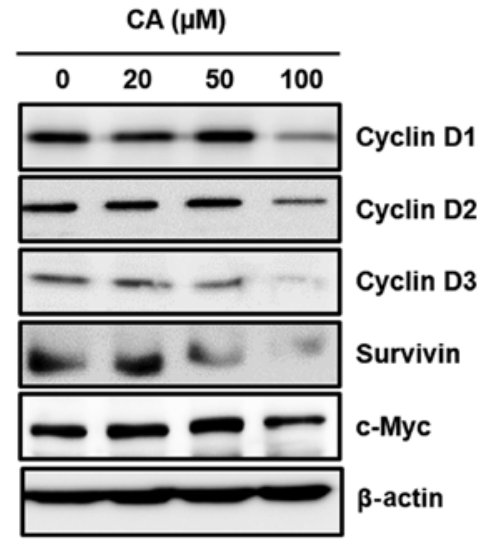

B

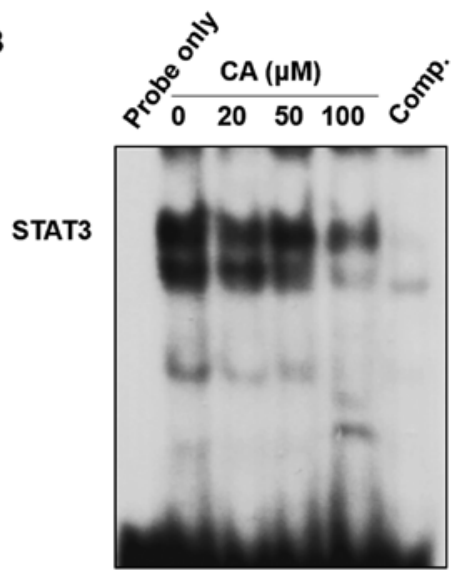

D

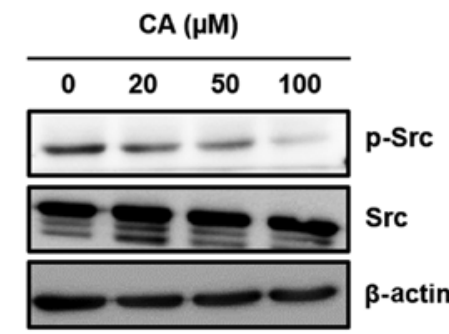

Figure 4. Carnosic acid (CA) inhibits constitutive activation of STAT3 and expression of its gene products. (A) Cells were treated with indicated concentrations of CA and the level of p-STAT3 (Y705) and p-STAT3 (S727) was detected by immunoblotting. (B) Nuclear extracts prepared from cells treated with CA as indicated was assessed for the DNA-binding of STAT3. (C) Cells were treated with indicated concentrations of CA for 24 h. Immunoblot analysis was performed to assess the expression of cyclin D1, D2 and D3, survivin and c-myc. (D) Immunoblot analysis was performed to assess the phosphorylation of Src. $\beta$-Actin was used as a loading control.

of CA on the phosphorylation of STAT3 and Src (Fig. 5A). To investigate the possible mechanism underlying the induction of apoptosis by CA via ROS generation, we also examined the cleavage of caspase-3 and PARP and expression of p53. As shown Fig. 5B and 5C, activation of p53, the cleavage of PARP and apoptosis induction through ROS generation was abolished by pretreatment of NAC in CA-treated Caki cells. These findings suggest that ROS play critical roles in CA-induced apoptosis in Caki cells.

\section{Discussion}

Cancer is a leading cause of death worldwide (37). Benign tumor is primarily removed by surgery and the residual cancer cells are eradicated by chemotherapy and/or radiotherapy. However, the chemotherapy regimens frequently cause various side effects, such as considerable death of healthy cells and drug tolerance. Thus, agents that specifically target tumor cells are ideal for cancer therapies. Based on this requirement, natural therapies, which take advantage of the abundant and vast resources of natural compounds derived from medicinal plants, are being developed to overcome the side effects of chemotherapeutic agents. The present study investigated the effect of CA, a major ingredient of medicinal herb Rosmarinus officinalis L., against human renal cancer cells and elucidated its mechanism of action.

Apoptosis is typically composed of two main pathways: the extrinsic pathway that mediates signals via death receptors, and the intrinsic pathway that involves mitochondrial dysfunction (38). The extrinsic pathway is provoked through the binding of cytokine ligands, such as FasL, TNF and TRAIL to the plasma membrane receptors (14). The interaction between ligands and receptors result in the formation of DISCs, which activate caspase- 8 and release the DISC into the cytoplasm (39). Caspase- 8 can activate caspase-3 directly or via release of cytochrome $\mathrm{c}$ mediated by mitochondria. The second pathway is the intrinsic pathway, which was triggered with a variety of stress stimuli, such as DNA damage and the actions of some oncoproteins (40). Signaling of this pathway is accompanied by the alteration in the expression of Bcl-2 family proteins, decreased mitochondrial membrane potentials, and the release of cytochrome c from the mitochondria to cytoplasm (41). The release of cytochrome $\mathrm{c}$ and regulation of Bcl-2 family proteins are critical processes in the mitochondria-mediated apoptosis $(41,42)$. In addition, the $\mathrm{Bcl}-2$ family proteins play a central function in inducing apoptosis and involve members with either pro- or anti-apoptotic activity (43). 
A

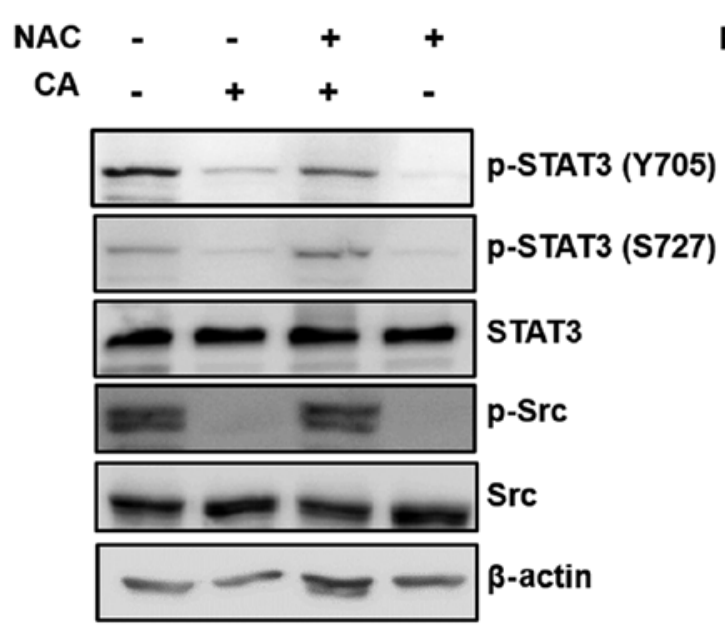

C

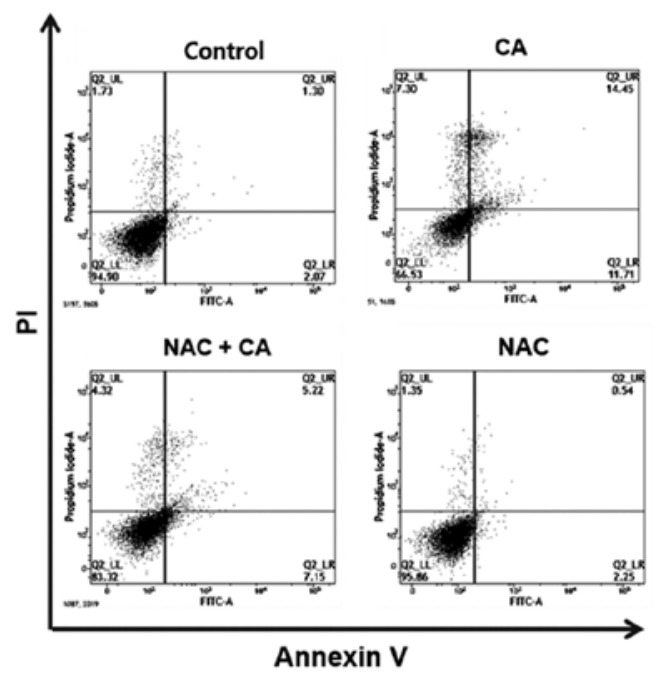

B

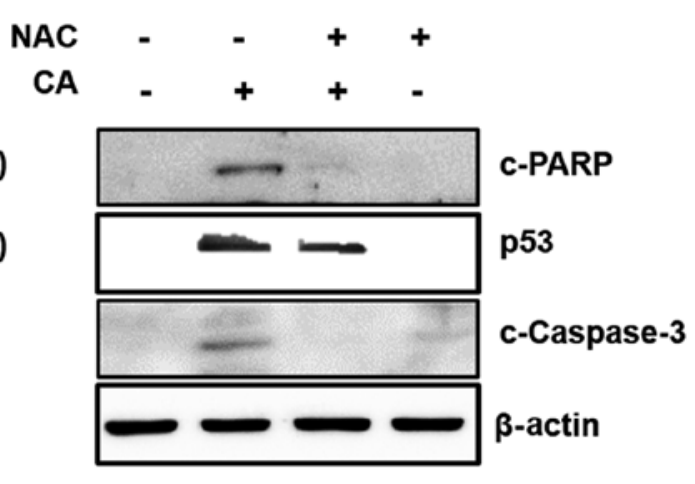

D

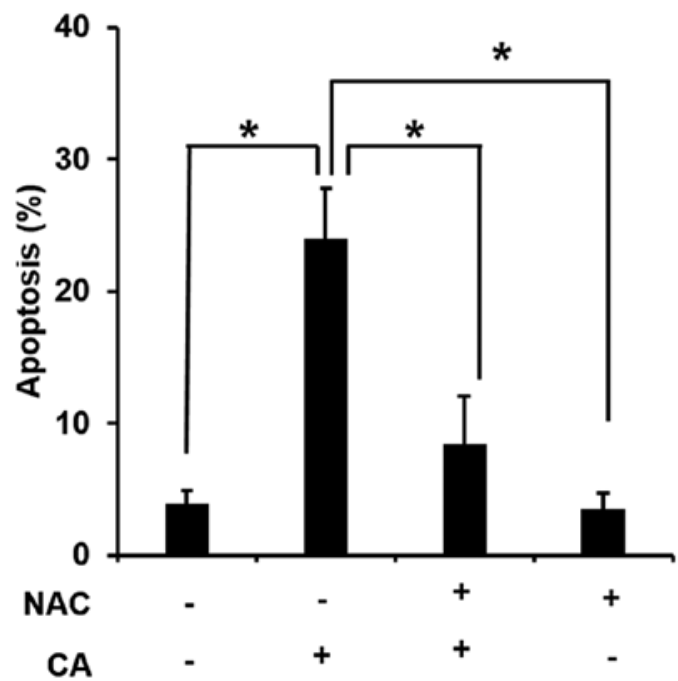

Figure 5. Roles of ROS in carnosic acid (CA)-induced inactivation of STAT3 signaling and apoptosis in Caki cells. Cells were treated with CA (100 $\mu \mathrm{M})$ for $24 \mathrm{~h}$ after pre-incubation with or without NAC (5 mM) for $1 \mathrm{~h}$. (A) Levels of p-STAT3 (Y705), p-STAT3 (S727) and p-Src were detected by western blot analysis. (B) Cleaved PARP, caspase-3 (cleaved form) and p53 were detected by immunoblotting. (C) Cells were treated with NAC (5 mM) $1 \mathrm{~h}$ before treatment with CA $(100 \mu \mathrm{M})$ for $24 \mathrm{~h}$. The apoptotic index (\%) was determined by flow cytometry. (D) This graph shows statistical analysis of apoptosis. Data are representative of three independent experiments. " $\mathrm{p}<0.001$, compared to control.

Our study demonstrated that cleaved PARP and procaspase- $9,-7$ and -3 , accompanied by decrease in the expression of anti-apoptotic proteins, such as Bcl-xL and Bcl-2, increase the expression of pro-apoptotic protein Bax in CA-treated Caki cells. These findings indicated that CA-induced apoptosis could partly be mediated through mitochondria-mediated apoptotic pathway. Cross-talk between the death-receptor and mitochondria-mediated pathway is achieved by Bid protein, which is altered by caspase- 8 . The death signal induced in the extrinsic pathway, for example, via DR4 and DR5, can lead to the disruption of mitochondrial membrane integrity $(8,44)$. The signal cascade is associated with the ability of caspase- 8 to proteolytically cleave Bid into truncated Bid (tBid). The pro-apoptotic protein tBid, a member of the Bcl-2 family, transfers to the mitochondria where it allows other proteins of the same family to combine with the outer mitochondrial membrane to release cytochrome $\mathrm{c}$. We found that incubation of cells with CA upregulated the expression of DR4 and DR5 and increased the proteolytic cleavage of caspase- 8 in Caki cells (data not shown). Taken together, the induction of apoptosis by $\mathrm{CA}$ involves both the extrinsic and the intrinsic pathways.

Tumor suppressor p53 is another important factor that affects the cellular response to drugs, while exert effects on growth inhibition and apoptosis induction (45). The p53 is sequestered in cytoplasm by binding with its inhibitory protein Mdm2, which possesses ubiquitin ligase property and plays an important role in p53 turnover. Thus, a decrease in Mdm2 level leads to stabilization of p53. In response to DNA damage, p53 is phosphorylated, dissociated from Mdm2 and translocated to the nucleus. Within the nucleus, phosphorylated p53 functions as a transcription factor that regulates transcrip- 


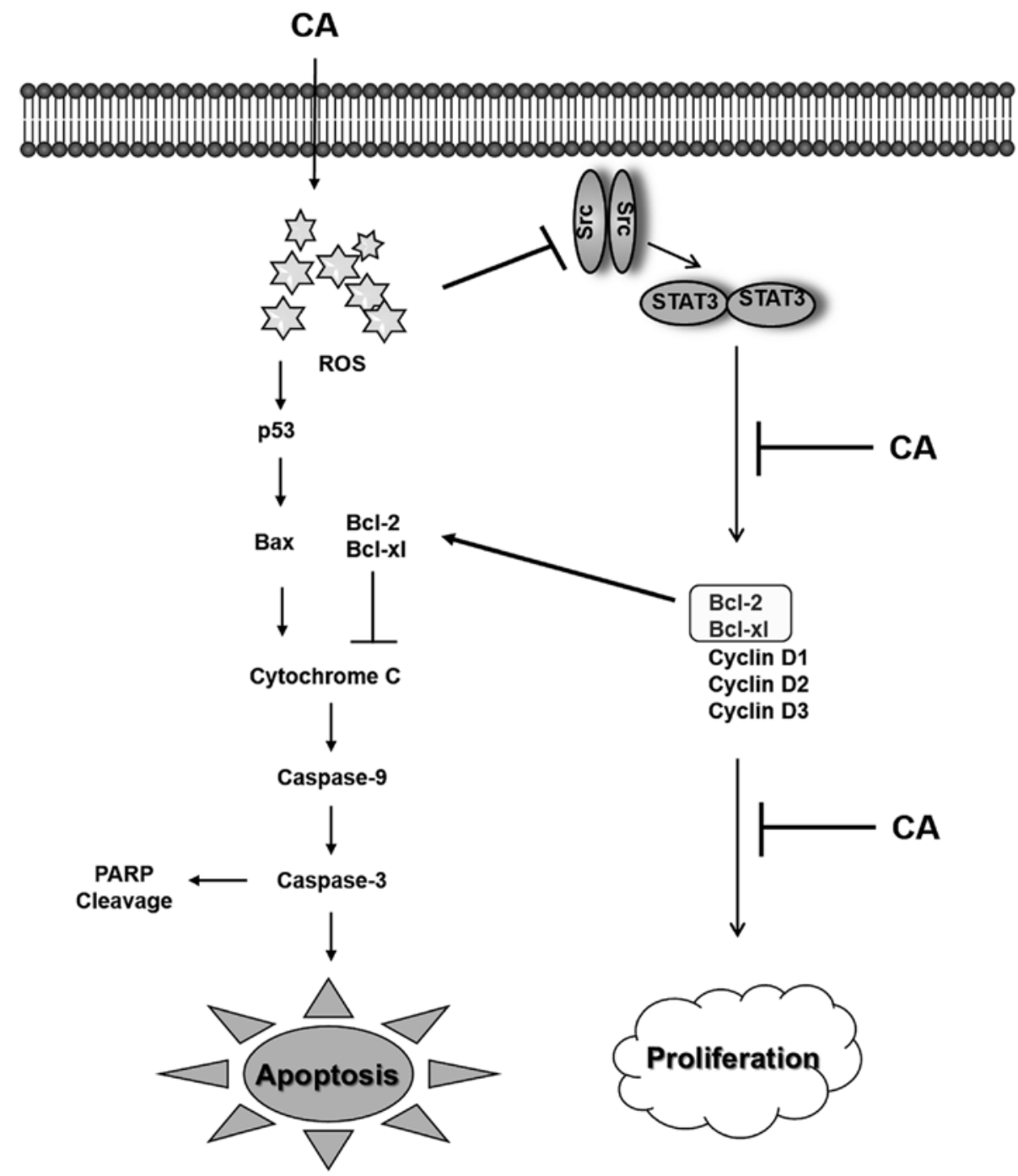

Figure 6. A diagram showing the proposed molecular mechanisms of apoptosis induction by CA in Caki cells.

tional activation of genes involved in cell cycle regulation and apoptosis $(46,47)$. The p53-dependent apoptosis is associated with the caspase cleavage and the expression of pro-apoptotic proteins, such as Bax (48). Moreover, p53 induces the cell cycle arrest through transcriptional activation of its several cell cycle regulatory gene products, such as $\mathrm{p} 21$ and $\mathrm{p} 27$. Thus, inhibiting $\mathrm{Mdm} 2$ expression and concomitantly elevating expression of p53. Taken together, these findings suggest that CA may cause apoptosis in a p53-dependent manner.

Since the activation of p53 occurs in response to oxidative stress (49), the effect of CA on ROS generation in Caki cells was examined. ROS, including free radicals such as superoxide, hydroxyl radicals $(\cdot \mathrm{OH})$, and the non-radical $\mathrm{H}_{2} \mathrm{O}_{2}$ are generated through multiple sources in the cells, such as the electron transport chain in mitochondria, ionizing radiations and enzymes (e.g., phagocytic and non-phagocytic NADPH oxidases, lipoxygenases and cycloxygenases) producing superoxide anions. Moreover, ROS is known to instigate the apoptotic cascade by causing damage to many cellular components including proteins, lipids, nucleic acid, and the mitochondria itself, which in turn facilitates the release of apoptogenic factors $(50,51)$. The present study showed that incubation with CA significantly increased the ROS level, which was scavenged by pretreatment of cells with NAC. Furthermore, NAC treatment rescued cells from CA-induced apoptosis by blocking the cleavage of PARP and the expression of p53. Thus, CA-induced ROS generation may activate p53, resulting in the downregulation of Bcl-2 and induction of Bax expression, thereby leading to the activation of caspases and induction of apoptosis.

Constitutive STAT3 activation has been related to a variety of tumors including breast, prostate and colon cancer (52). Recent studies have indicated that the STAT3 signaling pathway is closely associated with cell proliferation, differentiation and evasion of apoptosis $(53,54)$. The activation of STAT3 signaling involves phosphorylation of Y705 and S727 residues followed by dimerization and nuclear translocation, and subsequently DNA binding for the transcriptional activation of its target genes (55). Since CA abolished the expression of Bcl-2 and Bcl-xL, which are regulated by STAT3, the effect of CA on the activation of STAT3 signaling in Caki cells was examined. The present study revealed that CA blunted the constitutive phosphorylation of STAT3 and reduced the expression of its target genes D-series of cyclins, survivin and c-Myc. Intracellular kinases, such as Src, have been shown to phosphorylate STAT3. Thus, the inhibitory effect of CA on the 
phosphorylation of Src suggests that the compound interferes with STAT3 signaling pathway.

In conclusion, the present study demonstrates for the first time that $\mathrm{CA}$ induces both the extrinsic and intrinsic pathways of apoptosis in Caki cells through the generation of ROS and inactivation of STAT3 signaling (Fig. 6).

\section{Acknowledgements}

This study was supported by Basic Science Research Program through the National Research Foundation of Korea (NRF) funded by the Ministry of Science, ICT and Future Planning (2014R1A2A2A01004698).

\section{References}

1. Motzer RJ, Bander NH and Nanus DM: Renal-cell carcinoma. N Engl J Med 335: 865-875, 1996.

2. Mulders P, Figlin R, deKernion JB, Wiltrout R, Linehan M, Parkinson D, deWolf W and Belldegrun A: Renal cell carcinoma: Recent progress and future directions. Cancer Res 57: 5189-5195, 1997.

3. Santoni M, De Tursi M, Felici A, Lo Re G, Ricotta R, Ruggeri EM, Sabbatini R, Santini D, Vaccaro V and Milella M: Management of metastatic renal cell carcinoma patients with poor-risk features: Current status and future perspectives. Expert Rev Anticancer Ther 13: 697-709, 2013.

4. Huang MT, Ho CT, Wang ZY, Ferraro T, Lou YR, Stauber K, Ma W, Georgiadis C, Laskin JD and Conney AH: Inhibition of skin tumorigenesis by rosemary and its constituents carnosol and ursolic acid. Cancer Res 54: 701-708, 1994.

5. Chen D and Dou QP: Tea polyphenols and their roles in cancer prevention and chemotherapy. Int J Mol Sci 9: 1196-1206, 2008.

6. Kerr JF, Wyllie AH and Currie AR: Apoptosis: A basic biological phenomenon with wide-ranging implications in tissue kinetics. Br J Cancer 26: 239-257, 1972.

7. Earnshaw WC, Martins LM and Kaufmann SH: Mammalian caspases: Structure, activation, substrates, and functions during apoptosis. Annu Rev Biochem 68: 383-424, 1999.

8. Fulda S, Galluzzi L and Kroemer G: Targeting mitochondria for cancer therapy. Nat Rev Drug Discov 9: 447-464, 2010.

9. Panaretakis T, Pokrovskaja K, Shoshan MC and Grandér D: Interferon-alpha-induced apoptosis in U266 cells is associated with activation of the proapoptotic Bcl-2 family members Bak and Bax. Oncogene 22: 4543-4556, 2003.

10. Youle RJ and Strasser A: The BCL-2 protein family: Opposing activities that mediate cell death. Nat Rev Mol Cell Biol 9: 47-59, 2008.

11. Trachootham D, Lu W, Ogasawara MA, Nilsa RD and Huang P: Redox regulation of cell survival. Antioxid Redox Signal 10: 1343-1374, 2008.

12. Akgul C, Moulding DA and Edwards SW: Molecular control of neutrophil apoptosis. FEBS Lett 487: 318-322, 2001.

13. Kang YJ, Kim IY, Kim EH, Yoon MJ, Kim SU, Kwon TK and Choi KS: Paxilline enhances TRAIL-mediated apoptosis of glioma cells via modulation of c-FLIP, survivin and DR5. Exp Mol Med 43: 24-34, 2011.

14. Thorburn A: Death receptor-induced cell killing. Cell Signal 16 : 139-144, 2004.

15. Ashkenazi A: Targeting the extrinsic apoptosis pathway in cancer. Cytokine Growth Factor Rev 19: 325-331, 2008.

16. Neergheen VS, Bahorun T, Taylor EW, Jen LS and Aruoma OI: Targeting specific cell signaling transduction pathways by dietary and medicinal phytochemicals in cancer chemoprevention. Toxicology 278: 229-241, 2010.

17. Huang S: Regulation of metastases by signal transducer and activator of transcription 3 signaling pathway: Clinical implications. Clin Cancer Res 13: 1362-1366, 2007.

18. Niu G, Wright KL, Huang M, Song L, Haura E, Turkson J, Zhang S, Wang T, Sinibaldi D, Coppola D, et al: Constitutive Stat 3 activity up-regulates VEGF expression and tumor angiogenesis. Oncogene 21: 2000-2008, 2002.

19. Wang T, Niu G, Kortylewski M, Burdelya L, Shain K, Zhang S, Bhattacharya R, Gabrilovich D, Heller R, Coppola D, et al: Regulation of the innate and adaptive immune responses by Stat-3 signaling in tumor cells. Nat Med 10: 48-54, 2004.
20. Wang Y, Ma X, Yan S, Shen S, Zhu H, Gu Y, Wang H, Qin G and Yu Q: 17-hydroxy-jolkinolide B inhibits signal transducers and activators of transcription 3 signaling by covalently crosslinking Janus kinases and induces apoptosis of human cancer cells. Cancer Res 69: 7302-7310, 2009.

21. Yu h and Jove R: The STATs of cancer - new molecular targets come of age. Nat Rev Cancer 4: 97-105, 2004.

22. Chen YF, Yang JS, Chang WS, Tsai SC, Peng SF and Zhou YR: Houttuynia cordata Thunb extract modulates G0/G1 arrest and Fas/CD95-mediated death receptor apoptotic cell death in human lung cancer A549 cells. J Biomed Sci 20: 18, 2013.

23. Kim HG, Hwang YP and Jeong HG: Kahweol blocks STAT3 phosphorylation and induces apoptosis in human lung adenocarcinoma A549 cells. Toxicol Lett 187: 28-34, 2009.

24. Jalali-Heravi M, Moazeni RS and Sereshti H: Analysis of Iranian rosemary essential oil: Application of gas chromatography-mass spectrometry combined with chemometrics. J Chromatogr A 1218: 2569-2576, 2011.

25. Ninomiya K, Matsuda H, Shimoda H, Nishida N, Kasajima N, Yoshino T, Morikawa T and Yoshikawa M: Carnosic acid, a new class of lipid absorption inhibitor from sage. Bioorg Med Chem Lett 14: 1943-1946, 2004.

26. Almela L, Sánchez-Muñoz B, Fernández-López JA, Roca MJ and Rabe V: Liquid chromatograpic-mass spectrometric analysis of phenolics and free radical scavenging activity of rosemary extract from different raw material. J Chromatogr A 1120: 221-229, 2006.

27. Ramírez P, García-Risco MR, Santoyo S, Señoráns FJ, Ibáñez E and Reglero G: Isolation of functional ingredients from rosemary by preparative-supercritical fluid chromatography (Prep-SFC). J Pharm Biomed Anal 41: 1606-1613, 2006.

28. López-García S, Castañeda-Sanchez JI, Jiménez-Arellanes A, Domínguez-López L, Castro-Mussot ME, Hernández-Sanchéz J and Luna-Herrera J: Macrophage activation by ursolic and oleanolic acids during mycobacterial infection. Molecules 20: 14348-14364, 2015.

29. Ortuño J, Serrano R and Bañón S: Antioxidant and antimicrobial effects of dietary supplementation with rosemary diterpenes (carnosic acid and carnosol) vs vitamin $\mathrm{E}$ on lamb meat packed under protective atmosphere. Meat Sci 110: 62-69, 2015.

30. Gaya M, Repetto V, Toneatto J, Anesini C, Piwien-Pilipuk G and Moreno S: Antiadipogenic effect of carnosic acid, a natural compound present in Rosmarinus officinalis, is exerted through the C/EBPs and PPAR $\gamma$ pathways at the onset of the differentiation program. Biochim Biophys Acta 1830: 3796-3806, 2013.

31. Ibarra A, Cases J, Roller M, Chiralt-Boix A, Coussaert A and Ripoll C: Carnosic acid-rich rosemary (Rosmarinus officinalis L.) leaf extract limits weight gain and improves cholesterol levels and glycaemia in mice on a high-fat diet. Br J Nutr 106: 1182-1189, 2011.

32. Tsai CW, Liu KL, Lin YR and Kuo WC: The mechanisms of carnosic acid attenuates tumor necrosis factor- $\alpha$-mediated inflammation and insulin resistance in 3T3-L1 adipocytes. Mol Nutr Food Res 58: 654-664, 2014.

33. Wang T, Takikawa Y, Satoh T, Yoshioka Y, Kosaka K, Tatemichi Y and Suzuki K: Carnosic acid prevents obesity and hepatic steatosis in ob/ob mice. Hepatol Res 41: 87-92, 2011.

34. Xiang Q, Liu Z, Wang Y, Xiao H, Wu W, Xiao C and Liu X: Carnosic acid attenuates lipopolysaccharide-induced liver injury in rats via fortifying cellular antioxidant defense system. Food Chem Toxicol 53: 1-9, 2013.

35. Kundu JK, Shin YK, Kim SH and Surh YJ: Resveratrol inhibits phorbol ester-induced expression of COX-2 and activation of NF-kappaB in mouse skin by blocking IkappaB kinase activity. Carcinogenesis 27: 1465-1474, 2006.

36. Herr I and Debatin KM: Cellular stress response and apoptosis in cancer therapy. Blood 98: 2603-2614, 2001.

37. Jemal A, Bray F, Center MM, Ferlay J, Ward E and Forman D: Global cancer statistics. CA Cancer J Clin 61: 69-90, 2011.

38. Ouyang L, Shi Z, Zhao S, Wang FT, Zhou TT, Liu B and Bao JK: Programmed cell death pathways in cancer: A review of apoptosis, autophagy and programmed necrosis. Cell Prolif 45: 487-498, 2012.

39. Prasad S, Yadav VR, Kannappan R and Aggarwal BB: Ursolic acid, a pentacyclin triterpene, potentiates TRAIL-induced apoptosis through p53-independent up-regulation of death receptors: Evidence for the role of reactive oxygen species and JNK. J Biol Chem 286: 5546-5557, 2011.

40. Ghobrial IM, Witzig TE and Adjei AA: Targeting apoptosis pathways in cancer therapy. CA Cancer J Clin 55: 178-194, 2005. 
41. Wang X: The expanding role of mitochondria in apoptosis. Genes Dev 15: 2922-2933, 2001.

42. Garrido C, Galluzzi L, Brunet M, Puig PE, Didelot C and Kroemer G: Mechanisms of cytochrome c release from mitochondria. Cell Death Differ 13: 1423-1433, 2006.

43. Antonsson B and Martinou JC: The Bcl-2 protein family. Exp Cell Res 256: 50-57, 2000.

44. Han J, Goldstein LA, Gastman BR and Rabinowich H: Interrelated roles for Mcl-1 and BIM in regulation of TRAIL-mediated mitochondrial apoptosis. J Biol Chem 281: 10153-10163, 2006.

45. O'Connor PM, Jackman J, Bae I, Myers TG, Fan S, Mutoh M, Scudiero DA, Monks A, Sausville EA, Weinstein JN, et al: Characterization of the p53 tumor suppressor pathway in cell lines of the National Cancer Institute anticancer drug screen and correlations with the growth-inhibitory potency of 123 anticancer agents. Cancer Res 57: 4285-4300, 1997.

46. Giaccia AJ and Kastan MB: The complexity of p53 modulation: Emerging patterns from divergent signals. Genes Dev 12: 2973-2983, 1998.

47. Shieh SY, Ikeda M, Taya Y and Prives C: DNA damage-induced phosphorylation of p53 alleviates inhibition by MDM2. Cell 91: 325-334, 1997.

48. Gottlieb TM, Leal JF, Seger R, Taya Y and Oren M: Cross-talk between Akt, p53 and Mdm2: Possible implications for the regulation of apoptosis. Oncogene 21: 1299-1303, 2002.
49. Lotem J, Peled-Kamar M, Groner Y and Sachs L: Cellular oxidative stress and the control of apoptosis by wild-type p53, cytotoxic compounds, and cytokines. Proc Natl Acad Sci USA 93: 9166-9171, 1996.

50. Misra MK, Sarwat M, Bhakuni P, Tuteja R and Tuteja N: Oxidative stress and ischemic myocardial syndromes. Med Sci Monit 15: RA209-RA219, 2009.

51. Orrenius S, Gogvadze V and Zhivotovsky B: Mitochondrial oxidative stress: Implications for cell death. Annu Rev Pharmacol Toxicol 47: 143-183, 2007.

52. Kim DJ, Chan KS, Sano S and Digiovanni J: Signal transducer and activator of transcription 3 (Stat3) in epithelial carcinogenesis. Mol Carcinog 46: 725-731, 2007.

53. Kusaba T, Nakayama T, Yamazumi K, Yakata Y, Yoshizaki A, Inoue K, Nagayasu T and Sekine I: Activation of STAT3 is a marker of poor prognosis in human colorectal cancer. Oncol Rep 15: 1445-1451, 2006.

54. Lin L, Liu A, Peng Z, Lin HJ, Li PK, Li C and Lin J: STAT3 is necessary for proliferation and survival in colon cancer-initiating cells. Cancer Res 71: 7226-7237, 2011

55. Johnston PA and Grandis JR: STAT3 signaling: Anticancer strategies and challenges. Mol Interv 11: 18-26, 2011. 